\title{
Working paper: Neighborhood-level risk perceptions of extreme heat events across the U.S.
}

\author{
Peter D. Howe*. ${ }^{1}$, Jennifer R. Marlon ${ }^{2}$, Xinran $\mathrm{Wang}^{2}$, and Anthony Leiserowitz ${ }^{2}$ \\ ${ }^{1}$ Department of Environment and Society, Utah State University, Logan, Utah \\ 84322 \\ ${ }^{2}$ School of Forestry and Environmental Studies, Yale University, New Haven, \\ Connecticut 06511
}

April 27, 2018

\begin{abstract}
Extreme heat is the leading weather-related cause of death in the U.S., a threat that is exacerbated by global warming. Yet many individuals fail to perceive extreme heat as a serious risk. Thus, understanding Americans' perceptions of heat risk and how such perceptions vary geographically and across different populations is a critical precursor to encouraging adaptive behaviors - such as staying hydrated or refraining from outdoor activity - during heat waves. Using a large original survey dataset of 9,217 respondents, we model Americans' perceived risk to their health from extreme heat in every populated census tract across the nation. Nationally, risk perceptions are higher in southern states where mortality from heat waves is also highest. However, the extent of variation within states and metropolitan areas is similar to variation between states. Locally, risk perceptions are higher in areas with greater poverty and among minority populations that are more vulnerable to environmental risks in general. We identify highly vulnerable areas where risk perceptions currently lag heat-related mortality; without concerted adaptation efforts such vulnerability is likely to expand and intensify as heat exposure increases. Comprehensive estimates of extreme heat risk perceptions at the census tract level can support communication, education, and adaptation initiatives in existing and emerging areas most vulnerable to heat in the U.S.
\end{abstract}

\section{Main}

Extreme heat events are the leading weather-related cause of death in the U.S. and are projected to become more frequent and intense over the 21st century [1, 2, 3]. Mortality and morbidity from heat exposure can often be mitigated, however, if individuals perceive the risk, have access to necessary resources, and take appropriate precautionary action [4]. Mitigating the effects of extreme heat can be as simple as increasing fluid intake, using a fan, finding a cooler location, or avoiding over-exertion. Yet, if individuals do not perceive heat exposure to be a problem, then they may be less likely to obtain necessary resources and take appropriate actions. Despite the

*P.D.H. and J.R.M. designed and implemented the surveys, conducted analyses, and wrote the manuscript. X.W. performed analyses and modeling. A.L., J.R.M., and P.D.H. designed the study. All authors edited the manuscript. 
importance of risk perceptions in driving behavior, little effort has been directed to mapping risk perceptions because of the difficulty in obtaining comprehensive social survey data across large areas at fine spatial scales. Thus, while substantial effort and resources continue to focus on mapping variations in a population's exposure to and impacts from extreme heat $[5,6,7,8,9]$, which remains vital, comprehensive high resolution heat risk perception maps with a national extent have thus far been beyond scientific reach.

Here we apply a small-area estimation model based on new nationally representative survey data to estimate health risk perceptions of heat waves for every state, county, and census tract in the U.S. The model employs individual and socio-environmental predictors of heat risk perceptions and is validated using independent tract-level survey data. Mapping risk perceptions reveals the importance of physical factors such as local climate and land cover, along with demographic factors such as age and gender in shaping Americans' perceived risk to their personal, family's, and community's health during a heat wave. Risk perceptions exhibit substantial variation at multiple scales, with estimates across states showing similar variation to estimates across census tracts in major metropolitan areas. Results provide a new tool for communicators and decision makers to understand the geographic diversity in Americans' judgments about the health risks of extreme heat.

Extreme heat is one of the most severe environmental hazards to public health: it is the leading cause of weather-related mortality in the U.S., and has numerous impacts on vital social systems including food, water, energy and infrastructure $[1,4]$. Extreme heat events are also projected to intensify in frequency and severity due to climate change $[2,3,10]$, with even greater impacts in urban areas, due to heat island effects [11, 12, 13] and air pollution [14]. Increasing urbanization, migration to climates more prone to extreme heat, and an aging population that is more vulnerable to heat stress compounds the problem in the U.S. $[5,15,16]$.

Extreme heat typically becomes hazardous during heat waves, multi-day periods of excessively hot weather (often combined with high humidity) that, due to their severity or duration, pose risks to human health $[17,18]$. The point at which temperature and humidity levels threaten health, however, varies depending on factors such as physiological sensitivity, the ability to take protective action, individual psychological factors, and individual exposure $[9,16,19,20,21,22]$. Psychological factors that influence health risks include risk perceptions, which comprise beliefs and attitudes about the frequency, severity, and duration of extreme heat events, as well as the dangers of exposure. In addition to physical risk factors, previous research underscores the importance of such risk perceptions-among other social and behavioral factors-in increasing 
vulnerability to hazards and the impacts of climate change $[23,24,25,26,27]$. Vulnerability to extreme heat varies geographically at local to regional scales due to a variety of factors including differences in physical exposure to hot weather driven by climate and land cover, variation in demographic and health status characteristics associated with heat sensitivity, and availability of air conditioning, among others [28]. Few studies, however, have focused on heat wave risk perceptions specifically, or systematically collected data on risk perceptions at the national scale to how perceptions vary geographically or across demographic groups. Previous research has used qualitative case studies of subgroups of the population or surveys in a small number of individual cities $[29,30,31,32,33,34]$. There remains a large knowledge gap globally about heat risk perceptions and how to effectively communicate about the risk [35]. Societal vulnerability to extreme heat is increasingly understood as a function not only of demographics and access to resources, but also knowledge and perceptions [36]. Effective adaptation strategies to the risks of extreme heat, therefore, must address public perceptions and knowledge [13].

The urgency of understanding the determinants of heat wave vulnerability is compounded by global warming, which will exacerbate impacts due to higher average temperatures, more frequent temperature extremes, increased humidity, and increased weather variability [3, 37, 38]. Global warming will exacerbate extreme heat hazards in areas that already experience extreme heat, but the hazard will also spread to areas with little prior experience of health-threatening heat $[2,3]$. In such areas, risk perceptions will likely lag the changing risk environment since they are strongly influenced by a variety of cognitive and intuitive factors including personal experience [27]. The gap between perceptions and changing baseline risk will compound vulnerability if it reduces the likelihood of individuals to take precautionary actions. Thus it is important to understand how people currently perceive the risk of extreme heat at the appropriate geographic scales necessary to target resources and reduce population vulnerability.

\section{Small-area estimation from national survey data}

We use new nationally representative survey data and multilevel regression and poststratification (MRP), a small-area estimation method, to provide high-resolution, nationwide estimates of risk perceptions. We collected U.S. national survey data $(\mathrm{n}=9217)$ in 10 waves at two-week intervals during Summer 2015 using a representative online panel. Our survey instrument contained nine questions eliciting respondents' judgments of negative health effects from heat waves operationalized in terms of likelihood, severity, and worry. Respondents were asked to evaluate each aspect in terms of health risks to themselves (personal risks), family members (family risks), 
and others in their community (community risks). Here we present an aggregate index of overall heat risk perception for all nine items (Cronbach's $\alpha=0.95$ ). Respondents who did not answer all nine questions were omitted from the analysis $(\mathrm{n}=368)$.

We apply MRP to the national survey data to generate estimates of heat risk perceptions at the census tract level for all populated census tracts in the U.S. MRP is an emerging method developed to estimate public opinion (or other population estimates) at sub-national levels using multilevel regression modeling of survey data in combination with census data and other geographically varying predictors $[39,40,41]$. Recent research has applied and validated MRP to estimate patterns in public opinion across a range of sub-national scales relevant to decision making in the context of climate change [42, 43].

Our results are validated by comparing model estimates against estimates from independently conducted surveys (in randomly selected geographies) in two census tracts and eight states.

\section{Results}

Our heat risk perception index ranged from 0 to 100, with higher values indicating higher risk perceptions. People with higher risk perceptions were 1) more likely to think that a heat wave would occur in their community; 2) more likely to think that a heat wave, were it to happen in their community, would affect the health of themselves, their family, and others in their community; and 3) more worried about the effects of heat waves. Nationally, the mean heat risk perception index was 40. At the state level, estimates ranged from 31 to 45 . Overall, respondents perceived the risks of extreme heat to themselves (mean $=34.6, \mathrm{SD}=3.9$ ) to be lower than risks to their family (mean=39.6, $\mathrm{SD}=3.4$ ) or others in their community (mean=47.9, $\mathrm{SD}=3.5)$. An online visualization tool shows the spatial variations across the US at county and tract levels (Beta version for peer review: https://bit.ly/2q5wDPS).

Risk perceptions of extreme heat exhibit substantial variation from the local to regional scale in the U.S. At state level, there is a distinct north-south gradient in perceptions of harm from heat waves, with residents in southern states perceiving higher risk than those in northern states (Fig. 1). People in inland northern states in particular (e.g., North Dakota, Minnesota) exhibit lower risk perceptions than those in coastal states. Residents of Texas, Louisiana, and Nevada had the highest levels of perceived risk. Closer examination of state- $(\mathrm{SD}=3.8)$ and county-level $(\mathrm{SD}=4.2)$ heat risk perceptions also shows substantial variation (Fig. 2). The southernmost counties in Texas perceive the greatest potential harm from extreme heat, for example, as do counties in southern California and its Central Valley. In addition, highly populated counties 


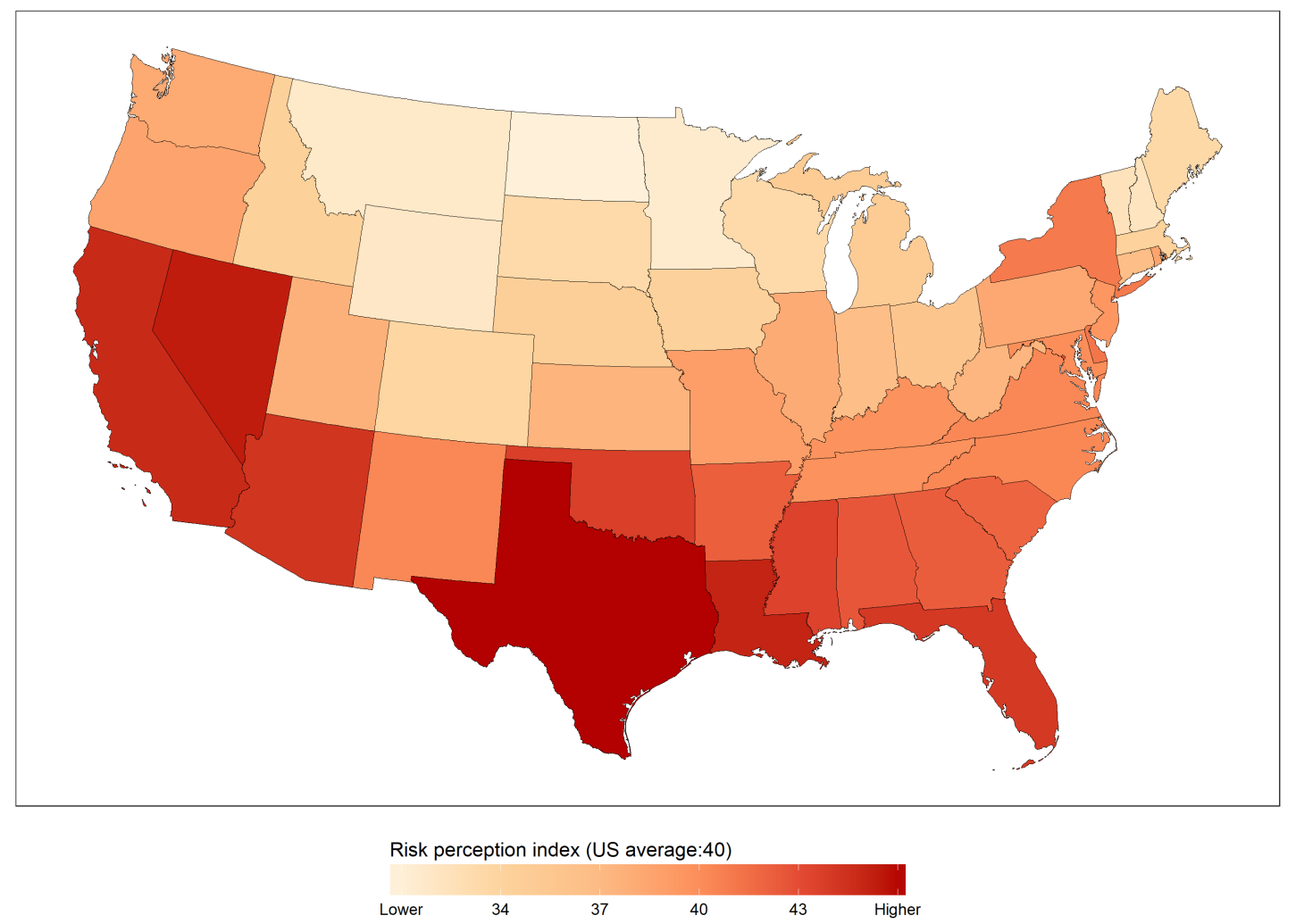

Figure 1: State level estimates of heat risk perception for the contiguous U.S. Values indicate mean estimated risk perception index for the population of each state $(\mathrm{SD}=3.8)$.

are important for determining the overall level of risk perception within a state. The gradient in extreme heat risk perceptions evident in the U.S. in both the state and county-level maps is consistent with the latitudinal temperature gradient and suggests that those living in warmer climates understandably perceive higher risks from extreme heat. Likewise, some of the lowest risk perceptions are in counties at high elevations with cooler climates, such as in the Rocky Mountains of Colorado, Wyoming, and Idaho. Lower-than-average risk perceptions are also evident in counties along the Appalachian Mountains. Such patterns highlight the influence of temperature as a key factor driving spatial variations in extreme heat risk perceptions; demographic influences, however, are also evident at the national scale. Higher-than average risk perceptions of extreme heat can be found, for example, in some counties with relatively high African American (e.g. along the Southern Black Belt in east-central Mississippi and Alabama) or Hispanic/Latino populations (e.g. in southern California and Texas).

Spatial patterns in heat risk perceptions also show strong features at the census tract level, with wide variation present even within the same counties (Fig. 3). Such patterns are not 

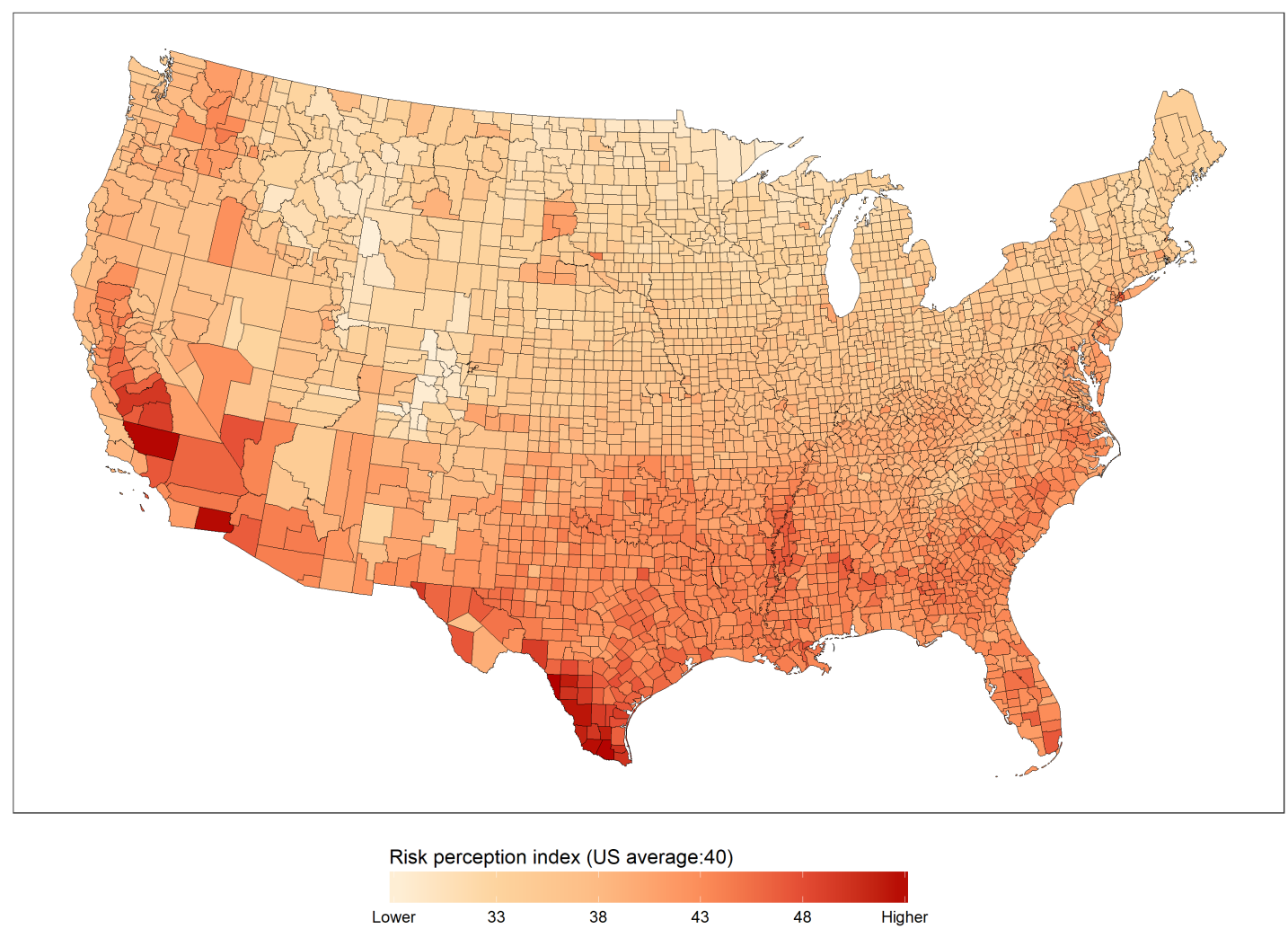

Figure 2: County level estimates of heat risk perception for contiguous U.S. counties. Values indicate mean estimated risk perception index for the population of each county $(\mathrm{SD}=4.2$ ). 
Los Angeles County, California

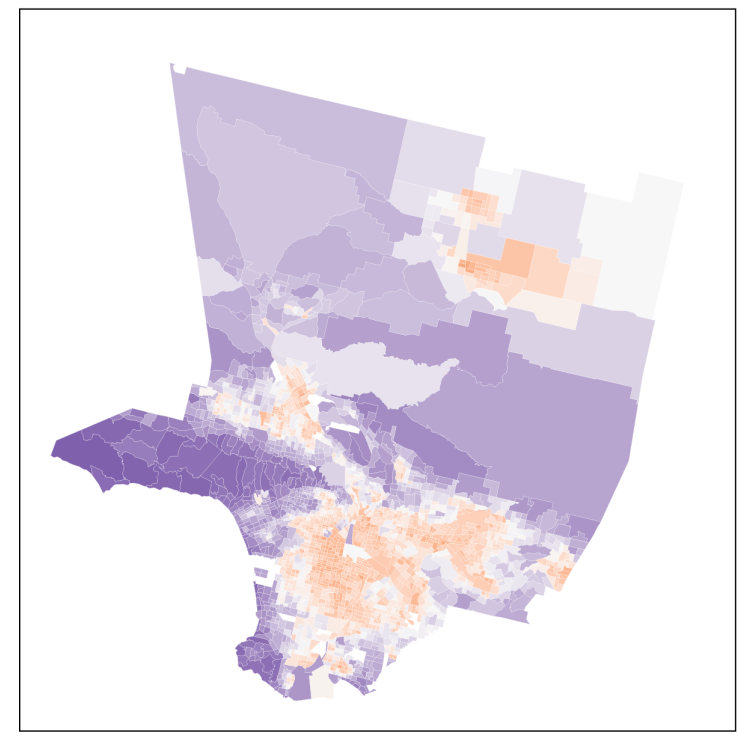

Harris County, Texas

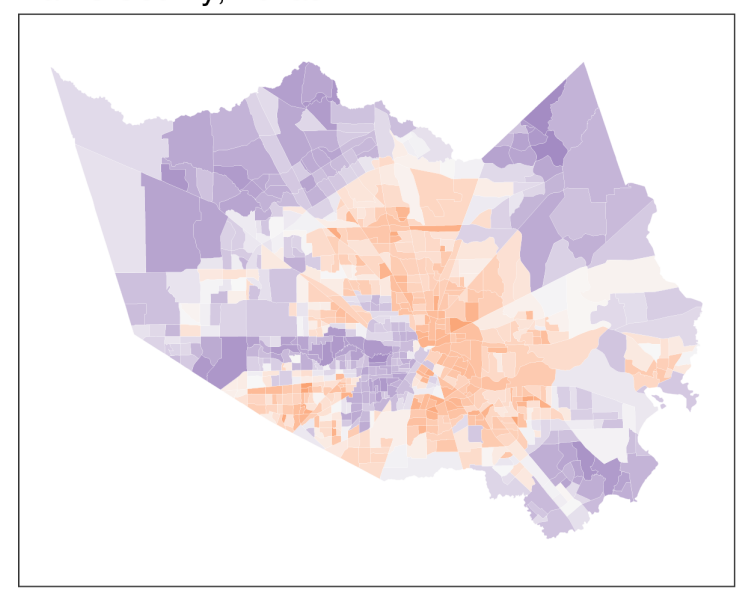

Difference from county average
Cook County, Illinois

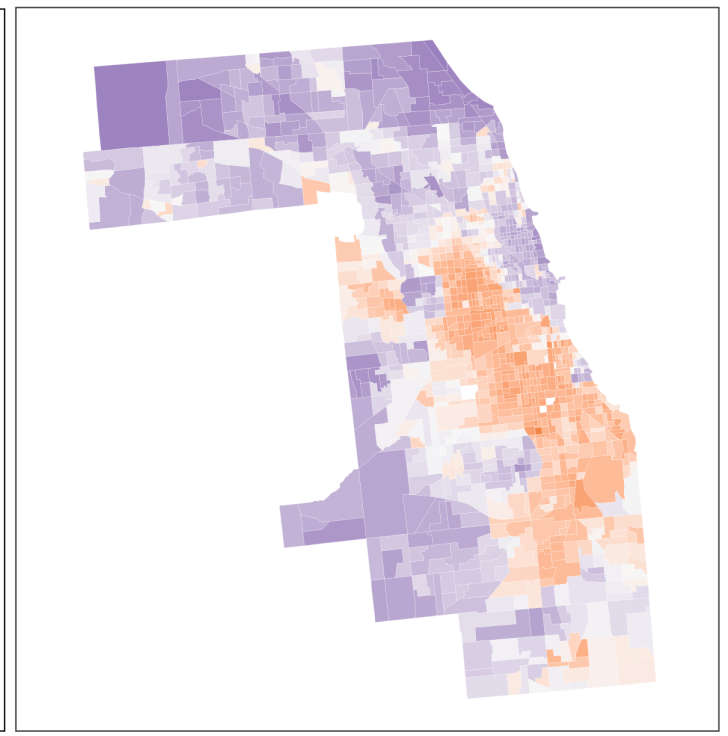

Maricopa County, Arizona

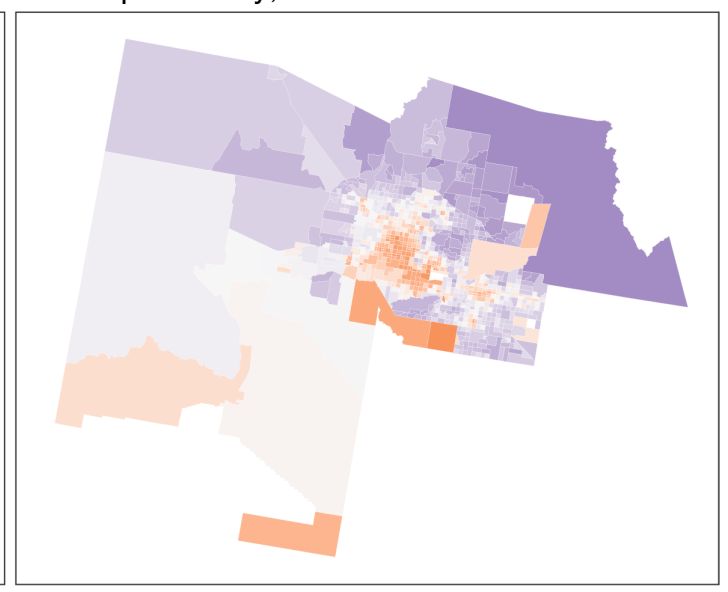

5

10

Figure 3: Tract level estimates of heat risk perception for the four largest U.S. counties by population. Tracts are shaded by the difference from the average for each county. From top left: Los Angeles County, California (mean=45, SD=4.1), Cook County, Illinois (mean=39, $\mathrm{SD}=4.5)$, Harris County, Texas (mean $=46, \mathrm{SD}=3.9)$, and Maricopa County, Arizona $($ mean=43, $\mathrm{SD}=3.8)$. 
wholly consistent with variations in temperature exposure. In examples from the four most populated counties, Los Angeles, California, Cook County, Illinois (Chicago), Harris County, Texas (Houston), and Maricopa County, Arizona (Phoenix), risk perceptions vary within counties by about 20 points $(\mathrm{SD}=3.8-4.5)$. In each case, the more densely populated urban tracts tend to exhibit higher relative risk perceptions than the suburban and rural areas surrounding the cities. Yet, while temperature changes may again partly explain these variations due to urban heat island effects, the spatial variability of risk perceptions within urban cores points to other factors. Close examination of the most densely populated areas (indicated by smaller tract sizes) reveals an urban core with relatively low risk perceptions of harm from extreme heat surrounded by a ring of tracts with higher perceived harm (especially, for example, in Harris County, Texas). Such a pattern reflects a feature of urban geography in many American cities explained primarily by differences in economic, demographic, and social factors [44]. Thus, within urban areas heat risk perceptions are strongly influenced by sociodemographics that are consistent with social vulnerability [45].

Model estimates were validated against independent mail surveys conducted in two census tracts in the communities of Brawley, Imperial County, California $(n=277)$ and Peoria, Peoria County, Illinois $(\mathrm{n}=364)$. Tracts were selected by first stratifying all U.S. counties with heatrelated mortality statistics recorded in the CDC WONDER database [46] into those with aboveand below-average per capita mortality and above- and below-average risk perceptions. One county was then randomly selected from each of the two groups that had higher-than-average heat-related deaths and either lower- or higher-than average risk perceptions. That is, one county had high heat-related deaths and higher-than-average risk perceptions (Imperial County, CA), and the other had high heat-related deaths and lower-than-average risk perceptions (Peoria County, IL). One census tract was then randomly selected within each of the two counties. Compared against these tract-level surveys, the mean absolute error of our MRP model estimates was 2.7 points (for CA and IL) (Fig. 4). We also validated our estimates against independent online surveys conducted in eight states. States were selected by stratifying all 48 contiguous states and the District of Columbia into population quartiles, and randomly selecting two states within each quartile. Compared against these state-level surveys, the mean absolute error of our MRP model estimates was 1.6 points, and the correlation of the model estimates to the state-level survey results was $\mathrm{r}=0.82$ (Fig. 5).

Within the two census tracts selected for our external validation surveys we see strong demographic patterns across race/ethnicity and gender. While white respondents have the lowest 


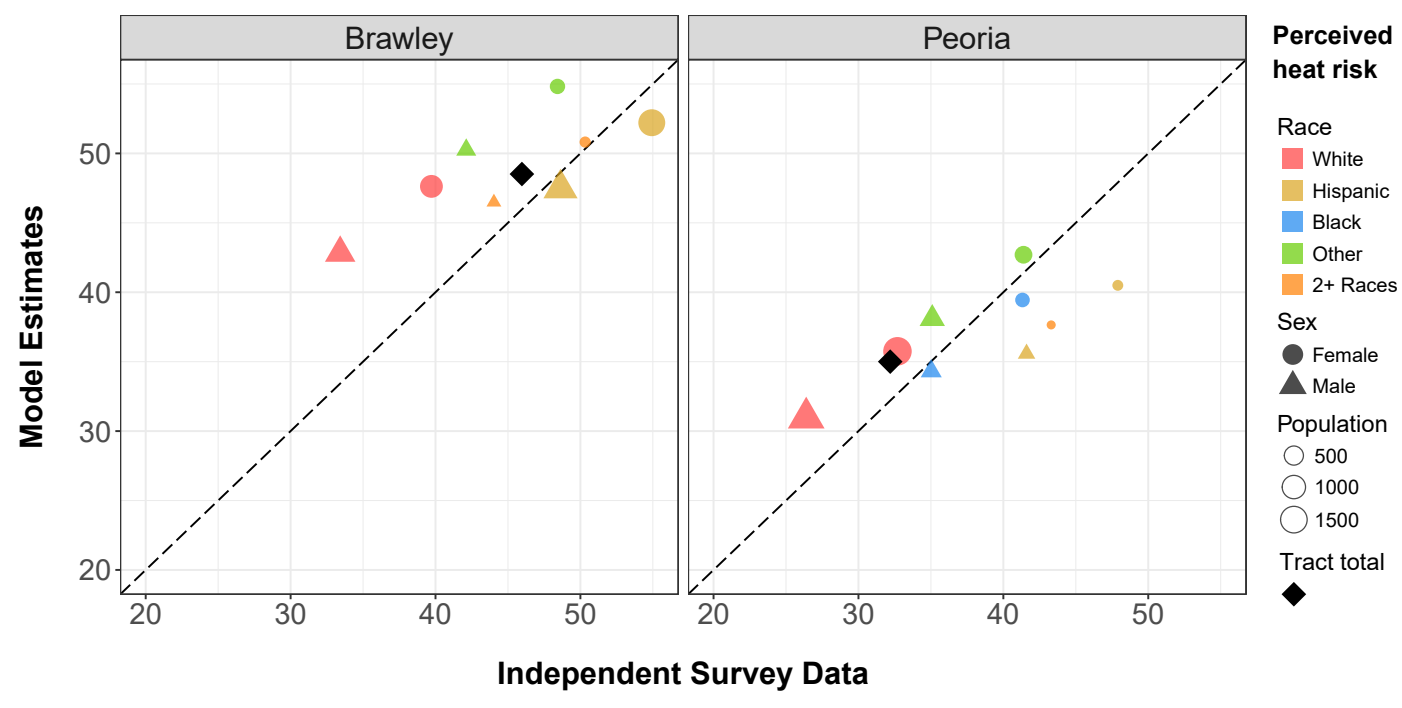

Figure 4: External validation of estimated risk perception index with independent survey estimates in randomly selected tracts in Imperial County (Brawley), California (left) and Peoria County, Illinois (right). The mean absolute difference between MRP model estimates and the external survey results was 2.7 points. The risk perception index is generally higher in Brawley than in Peoria. In both census tracts, Hispanic females have the highest risk perceptions while white males have the lowest.

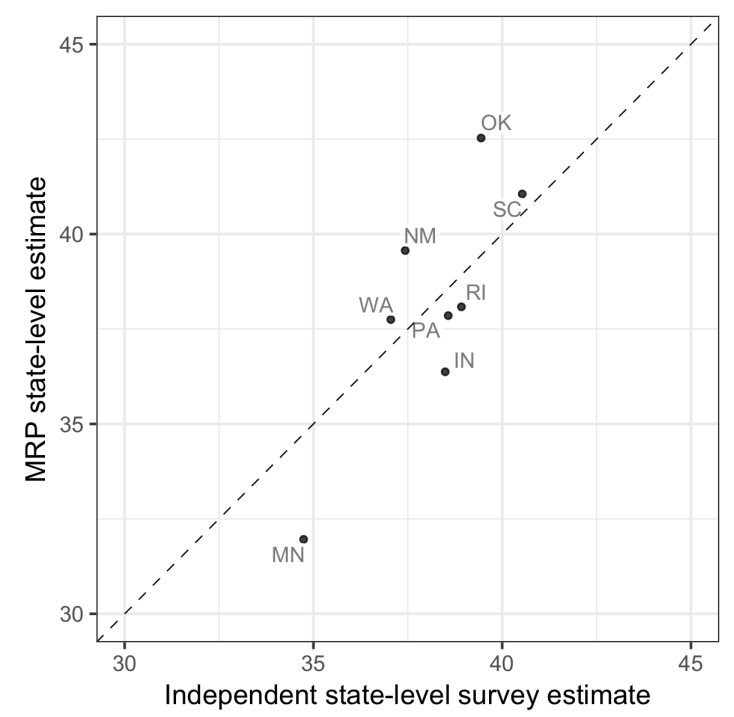

Figure 5: External validation comparison of estimated risk perception index with mean-centered independent survey estimates in eight randomly selected states. The mean absolute difference between MRP model estimates and the external survey results was 1.6 points. Estimates were correlated at $\mathrm{r}=0.82$. 
heat risk perceptions, Hispanic respondents have the highest risk perceptions in both tracts. Women tend to perceive higher risks from extreme heat than men. Estimated heat risk perceptions overall are 14 percentage points higher in the Imperial County, California tract than in the Peoria County, Illinois tract, which also illustrates regional-scale geographic differences.

Heat-related mortality data are available at the state level [46], which allows for a comparison between recent mortality and risk perception estimates. We see a generally positive relationship between risk perception and mortality from 1999-2015 (Fig. 6) ( $r=0.57$ ). However, regional patterns are also evident in this comparison: most states in the South have higher risk perceptions than would be predicted by their per capita mortality, while most states in the Midwest have lower risk perceptions than would be predicted by their mortality rate. These patterns may indicate some degree of existing adaptation in states with high risk perceptions and lower than expected mortality. For example, the heat risk perception index is 10 points higher in California than Wisconsin, yet mortality is similar in the two states $(0.2$ per 100,000) despite greater population exposure to extreme heat in California. Similarly, mortality is comparable between Texas and Kansas (0.3 per 100,000), yet the heat risk perception index is 7.5 points higher in Texas.

U.S. population exposure to extreme heat will continue to grow in the 21st century under most climate scenarios, driven by both changes in climate, population growth, and shifts in population distribution to more exposed areas [5]. We compare our risk perception estimates at the census division level to an ensemble mean scenario of population exposure for 20412070 reported by Jones et al. [5]. Risk perception estimates and population exposure are highly correlated both under the base period (1971-2000; $\mathrm{r}=0.77)$ and future projections (20412070; $\mathrm{r}=0.80$ ). Population exposure and risk perceptions are highest in the West-South Central division (including Texas, Oklahoma, Arkansas, and Louisiana). Risk perceptions are lower than expected, based on current and projected population exposure, in the Mountain division (including the states of Arizona, Nevada, Colorado, Utah, New Mexico, Montana, Idaho, and Wyoming).

\section{Discussion and conclusions}

The development of estimates of extreme heat risk perceptions that integrate sociodemographic as well as physical contextual factors can improve our understanding of spatial variability and scale-dependent patterns in these perceptions. The factors most important for determining the spatial patterns in risk perceptions appear to vary by geographic scale. At the state and county 


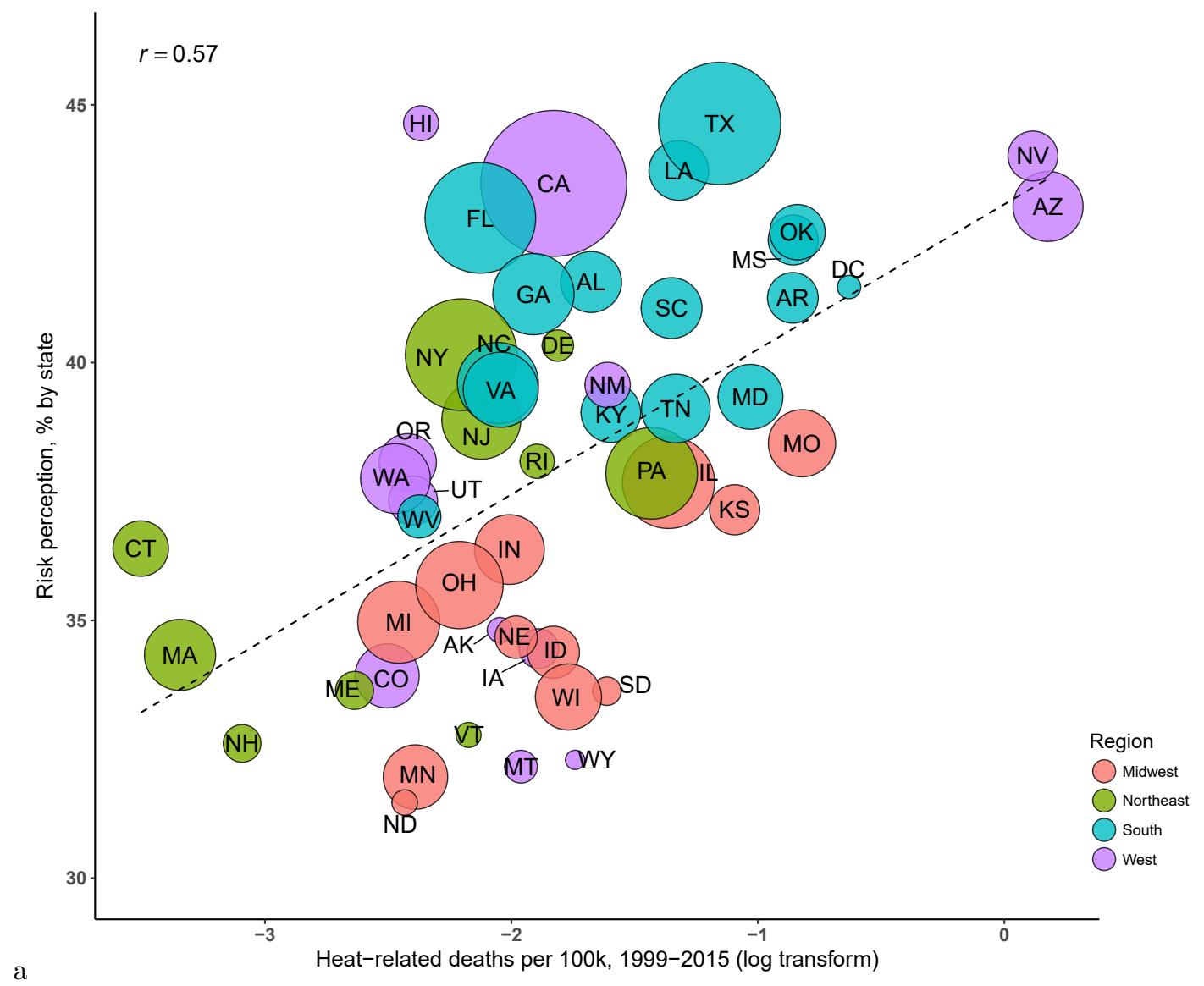

Figure 6: Risk perception as compared to heat-related mortality (MCD-ICD 10 code T67) at the state level, 1999-2015 [46]. 


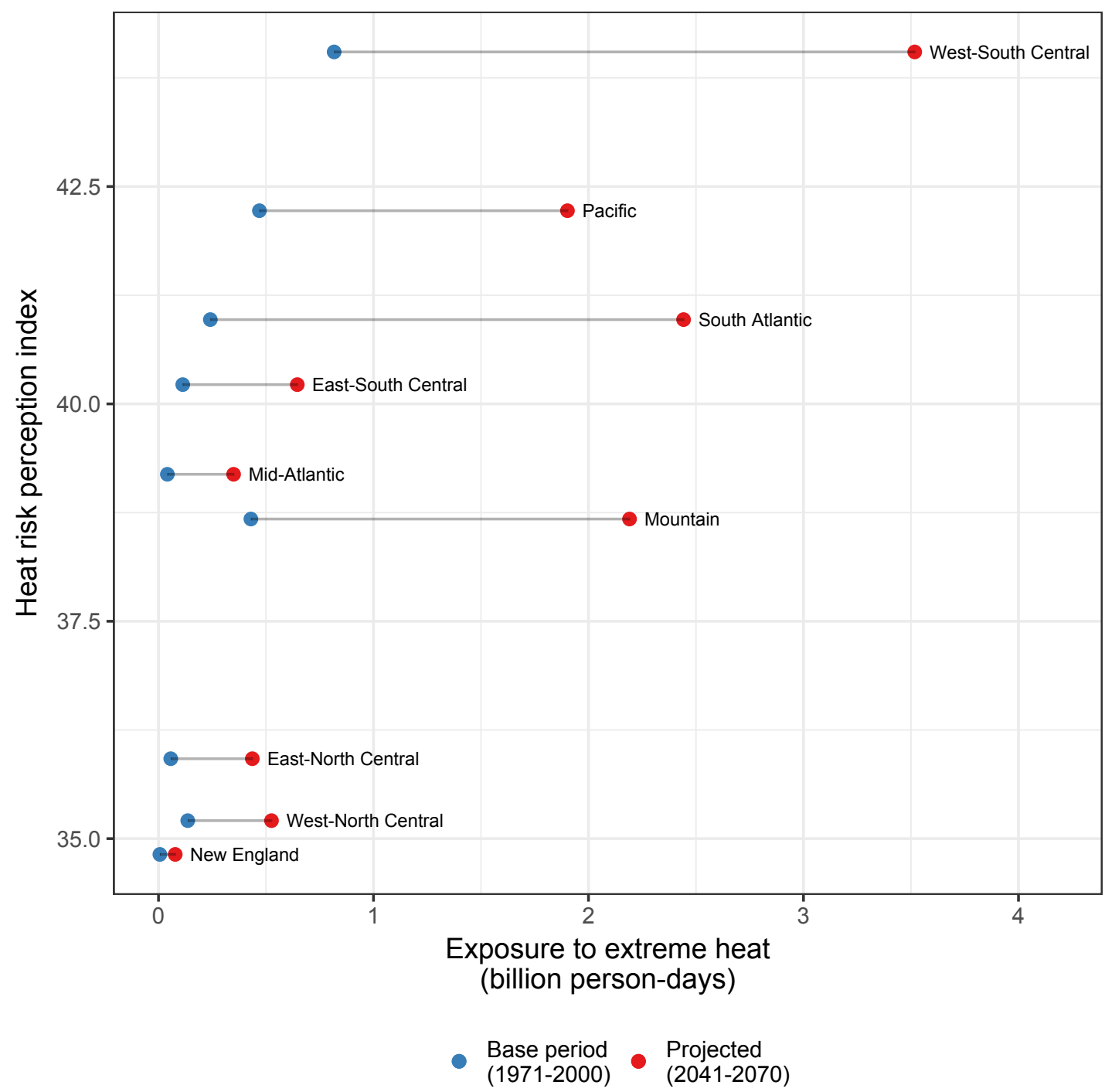

Figure 7: Heat risk perception index by projected change in aggregate exposure to extreme heat across nine U.S. census divisions. Exposure projections courtesy Jones et al. (2015) [5]. 
level, risk perceptions are consistent with differences in average temperatures. At local (city and neighborhood) scales, however, variation in risk perceptions are more strongly influenced by sociodemographic factors. In both cases, differences in perceptions are consistent with variation in both physical and social vulnerability to the hazard.

Increasing atmospheric greenhouse gas concentrations that are causing global temperatures to rise are also having an effect on the U.S., where mean temperatures have increased by $1.3^{\circ} \mathrm{F}$ to $1.9^{\circ} \mathrm{F}$ since record keeping began in 1895 [47]. As the climate continues to warm, populations in northern states and at higher elevations will become more exposed to extreme heat [3]. The rate at which individual's risk perceptions change, however, is unknown, and may lead to a growing gap between perceptions and exposure if risk perceptions do not keep pace with the changing climate. There is growing evidence that rising greenhouse gases are already affecting some characteristics (e.g., likelihood, severity) of heat waves [48] and projections of future climate change indicate that heat will become an increasing problem [49]. Populations in areas that already experience frequent extreme heat, such as the U.S. South and Southwest, will be more exposed to extreme heat, but may be able to leverage existing infrastructure and experiential knowledge to cope with more frequent hot weather. Populations in areas with lower exposure, such as those in northern states, may become increasingly at risk of negative health impacts from extreme heat as exposure exacerbates extreme heat events beyond the range of previous experience.

An analysis of city to national-scale trends in heat-related mortality found evidence that populations in the US have indeed become more resilient to heat over time, even when accounting for increases in the use of air conditioning [50]. Despite this increased resilience, however, an increase in average temperatures by $5^{\circ} \mathrm{F}$ (central climate projection) would lead to an additional 1,907 deaths per summer across 105 US cities [50]. A better understanding of the variation in Americans' risk perceptions of extreme heat may help further improve resilience to increasing heat in the coming decades.

Mapping model estimates reveals that risk perceptions of extreme heat appear to be scale dependent. Local climate, land cover, and other contextual factors shape risk perceptions alongside demographic predictors, but physical factors appear to be more important in driving national scale responses, whereas sociodemographic predictors are more relevant at finer scales. In addition, variation among states is similar to variation among census tracts in major metropolitan areas. Comparisons between Americans' current risk perceptions and future exposure to extreme heat suggest that residents of Mountain region states perceive less risk, on average, than those 
in other states with comparable exposure levels. Given that risk perceptions motivate adaptive responses, future efforts designed to increase awareness about the health risks of extreme heat may become particularly important in Mountain states, as well as in South Atlantic states, where future exposure is expected to increase the most. These results provide insights and a new tool for communicators and decision makers to understand the geographic diversity in Americans' judgments about the health risks of extreme heat, and point towards the need for additional analyses that can help identify areas where gaps (or lack of concordance) between actual and perceived risk may exist, or may grow in the future.

\section{Methods}

We construct an aggregate index of heat risk perception using our three groups of three questions in an online survey instrument designed to elicit risk judgments of negative health effects from heat waves operationalized in terms of likelihood, severity, and worry. Respondents used a slider bar to indicate their answer on a 0-100 scale. Respondents answered each question for a) "Your health;" b) "The health of others in your family;" and c) "The health of others in your community." Our questions were as follows: 1) "A heat wave is a period of unusually and uncomfortably hot weather. Thinking about your local area, how likely is it, if at all, that each of the following will be harmed by a heat wave in the next five years? If you're not sure, just give your best estimate." Response options range from $0 \%$ ("Definitely will not be harmed") to $100 \%$ (Definitely will be harmed). We also include a separate response option of "[w]ill not be harmed because a heat wave will not occur." 2) "If a heat wave were to occur in your local area, how much, if at all, do you think it would harm the following?" Response options ranged from 0 ("Would cause no harm at all") to 100 ("Would cause extreme harm"). 3) "How worried, if at all, are you about the effects of heat waves on the following?" Response options ranged from 0 ("Not worried at all") to 100 ("Extremely worried"). The aggregate index of all nine items has high internal consistency (Cronbach's $\alpha=0.95$ ).

Predicting heat wave risk perceptions at the tract level using multilevel regression and poststratification (MRP) proceeded through several stages, from variable and model selection to testing and validation. In MRP, a multilevel regression model is fit to an individual-level dependent variable using a combination of individual-level demographic predictors, grouped random effects, and group-level predictors across geographic units within the dataset. In the second step, poststratification, the fitted model is applied to the population of the study area across each demographic-geographic type within the population, using census data cross-tabulated across 
each type. Estimates for each demographic-geographic type can then be aggregated by their population to produce estimates for every geographic unit.

Our individual-level model uses age group, gender, and race/ethnicity as predictors, with an interaction term for age by gender by race/ethnicity. Individuals are grouped geographically according to their census tract, county, state, and census division. In addition to using fixed effects as in classical regression, the multilevel model uses random effects for grouping variables. Random effects are related to each other by their hierarchical structure and thus are partially pooled towards their group mean. Greater pooling occurs for smaller groups and when grouplevel variance is low. Group-level predictors are also used to improve model fit [40,41] and are based on respondents' geographic location. Based on exploratory analyses employing Random Forest (RF) analysis [51] that considered dozens of potential geographically varying census, climate, and land cover variables suggested by previous research, we included educational attainment, poverty, and disability status; impervious surface land cover; and gridded long-term mean temperature as tract-level predictors. For poststratification we utilize 2015 5-year American Community Survey data cross-tabulated by age group, gender, and race/ethnicity across all states, counties, and U.S. census tracts. Although there is a strong theoretical basis for selecting several sociodemographic factors in a model of heat wave risk perceptions, census and other datasets provide many different measures of most factors. RF ranks variables by their predictive importance, which we compared for four indices including personal harm, harm to one's family, and community harm, and an overall risk perception index that combined these three, resulting in four indices. We also compared the RF results for both binary and continuous outcomes, resulting in a total of eight indices. Age, race/ethnicity, education, disability, various measures of income, temperature, and the proportion of impervious surfaces in the tract consistently ranked among the top ten predictors in the RF analysis. Model selection proceeded by comparing predictions and errors across the reduced variable sets identified from the RF analysis.

We specify our model as follows, predicting heat risk perceptions $(y)$ for each individual $i$ :

$$
y_{i} \sim N\left(\gamma^{0}+\alpha_{j[i]}^{\text {race }}+\alpha_{k[i]}^{\text {age }}+\alpha_{l[i], D=d}^{\text {gender }}+\alpha_{j[i], k[i], l[i]}^{\text {race.age.gender }}+\alpha_{t[i]}^{\text {tract }}, \sigma_{y}^{2}\right),
$$

where 


$$
\begin{gathered}
\alpha_{j}^{\text {race }} \sim N\left(0, \sigma_{\text {race }}^{2}\right) \text { for } j=1, \ldots, 5 \\
\alpha_{k}^{\text {age }} \sim N\left(0, \sigma_{\text {age }}^{2}\right) \text { for } k=1, \ldots, 10 \\
\alpha_{l}^{\text {gender }} \sim N\left(0, \sigma_{\text {gender }}^{2}\right) \text { for } l=1,2 \\
\alpha_{j, k, l}^{\text {race.age.gender }} \sim N\left(0, \sigma_{\text {race.age.gender }}^{2}\right) \text { for } j=1, \ldots 5 ; k=1, \ldots 10 ; l=1,2 \\
\alpha_{t}^{\text {tract }} \sim N\left(\alpha_{r[t]}^{\text {region }}+\alpha_{s[t]}^{\text {state }}+\alpha_{c[t]}^{\text {county }}+\gamma^{\text {tmean }} \operatorname{tmean}_{t}+\gamma^{\text {landcover }_{\text {landcover }}+}+\right. \\
\left.\gamma^{\text {education }} \text { education }_{t}+\gamma^{\text {lowincome }}{ }^{\text {lowincome }}+\gamma^{\text {disability65 }} \operatorname{disability}_{t}, \sigma_{\text {tract }^{2}}^{2}\right) \text { for } t=1, \ldots, 6994 \\
\alpha_{r}^{\text {region }} \sim N\left(0, \sigma_{\text {region }}^{2}\right) \text { for } r=1, \ldots, 9 \\
\alpha_{s}^{\text {state }} \sim N\left(0, \sigma_{\text {state }}^{2}\right) \text { for } s=1, \ldots, 51 \\
\alpha_{c}^{\text {county }} \sim N\left(0, \sigma_{\text {county }}^{2}\right) \text { for } c=1, \ldots, 1524
\end{gathered}
$$

Each variable is indexed over individual $i$ and over response categories $j, k, l, r, s, c$, and $t$ for race, age, gender, state, region, county, and census tract geography variables, respectively. The tract variable is further modeled as a function of region, state, county, and a series of geographylevel covariates including the mean of daily mean summer (JJA) temperature within the census tract (1981-2010) from the Daymet dataset[52], the mean percentage imperviousness within the tract in 2011 from the National Land Cover Dataset [53], the percentage of the adult population with a bachelors degree or higher in 2014 [54], the percentage of households receiving benefits from the Supplemental Nutrition Assistance Program (SNAP) in 2014 [54], and the percentage of residents age 65 and over with disability status in 2014 [54]. The tract-level estimates are aggregated to create the county-level and state-level estimates. The models are fitted using the lmer function in the $\mathrm{R}$ package lme4; the lmer function fits the model using restricted maximum likelihood. 


\section{Acknowledgments}

This research was supported by the National Science Foundation Decision, Risk, and Management Sciences program (SES-1459903). We thank Ed Maibach for support and comments. Thanks to Swetha Kolluri, Yajie Li, Emily Esplin, Forrest Schoessow, and Kirsten Goldstein for contributions to the data analysis. 


\section{References}

[1] Kevin A. Borden and Susan L. Cutter. Spatial patterns of natural hazards mortality in the United States. International Journal of Health Geographics, 7(1):64, December 2008. ISSN 1476-072X. doi: 10.1186/1476-072X-7-64. URL http://www.ij-healthgeographics .com/ content/7/1/64/abstract.

[2] IPCC. Climate Change 2014: Impacts, Adaptation, and Vulnerability. Part A: Global and Sectoral Aspects. Contribution of Working Group II to the Fifth Assessment Report of the Intergovernmental Panel on Climate Change [Field, C.B., V.R. Barros, D.J. Dokken, K.J. Mach, M.D. Mastrandrea, T.E. Bilir, M. Chatterjee, K.L. Ebi, Y.O. Estrada, R.C. Genova, B. Girma, E.S. Kissel, A.N. Levy, S. MacCracken, P.R. Mastrandrea, and L.L. White (eds.)]. Cambridge University Press, Cambridge, United Kingdom and New York, NY, USA, 2014.

[3] Camilo Mora, Bénédicte Dousset, Iain R. Caldwell, Farrah E. Powell, Rollan C. Geronimo, Coral R. Bielecki, Chelsie W. W. Counsell, Bonnie S. Dietrich, Emily T. Johnston, Leo V. Louis, Matthew P. Lucas, Marie M. McKenzie, Alessandra G. Shea, Han Tseng, Thomas W. Giambelluca, Lisa R. Leon, Ed Hawkins, and Clay Trauernicht. Global risk of deadly heat. Nature Climate Change, advance online publication, June 2017. ISSN 1758-678X. doi: 10. 1038/nclimate3322. URL https://www.nature.com/nclimate/journal/vaop/ncurrent/ full/nclimate3322.html.

[4] George Luber and Michael McGeehin. Climate Change and Extreme Heat Events. American Journal of Preventive Medicine, 35(5):429-435, November 2008. ISSN 0749-3797. doi: 10.1016/j.amepre.2008.08.021. URL http://www. sciencedirect.com/science/article/ pii/S0749379708006867.

[5] Bryan Jones, Brian C. O’Neill, Larry McDaniel, Seth McGinnis, Linda O. Mearns, and Claudia Tebaldi. Future population exposure to US heat extremes. Nature Climate Change, advance online publication, May 2015. ISSN 1758-678X. doi: 10.1038/nclimate2631. URL http://www .nature.com/nclimate/journal/vaop/ncurrent/full/nclimate2631. html.

[6] Cunrui Huang, Adrian Gerard Barnett, Xiaoming Wang, Pavla Vaneckova, Gerard FitzGerald, and Shilu Tong. Projecting future heat-related mortality under climate change scenarios: a systematic review. Environmental health perspectives, 119(12):1681, 2011. 
[7] A. G. Barnett, S. Hajat, A. Gasparrini, and J. Rocklöv. Cold and heat waves in the United States. Environmental Research, 112:218-224, January 2012. ISSN 0013-9351. doi: 10.1016/j.envres.2011.12.010. URL http://www.sciencedirect.com/science/article/ pii/S001393511100315X.

[8] Kim Knowlton, Barry Lynn, Richard A Goldberg, Cynthia Rosenzweig, Christian Hogrefe, Joyce Klein Rosenthal, and Patrick L Kinney. Projecting heat-related mortality impacts under a changing climate in the new york city region. American Journal of Public Health, 97(11):2028-2034, 2007.

[9] David M. Hondula, Robert E. Davis, Michael V. Saha, Carleigh R. Wegner, and Lindsay M. Veazey. Geographic dimensions of heat-related mortality in seven U.S. cities. Environmental Research, 138:439-452, April 2015. ISSN 0013-9351. doi: 10.1016/j.envres.2015.02.033. URL http://www.sciencedirect.com/science/article/pii/S0013935115000687.

[10] Tom K. R. Matthews, Robert L. Wilby, and Conor Murphy. Communicating the deadly consequences of global warming for human heat stress. Proceedings of the National Academy of Sciences, 114(15):3861-3866, April 2017. ISSN 0027-8424, 1091-6490. doi: 10.1073/pnas. 1617526114. URL http://www.pnas.org/content/114/15/3861.

[11] Eugenia Kalnay and Ming Cai. Impact of urbanization and land-use change on climate. Nature, 423(6939):528-531, May 2003. ISSN 0028-0836. doi: 10.1038/nature01675. URL http://www. nature.com/nature/journal/v423/n6939/abs/nature01675.html.

[12] Dan Li and Elie Bou-Zeid. Synergistic Interactions between Urban Heat Islands and Heat Waves: The Impact in Cities Is Larger than the Sum of Its Parts*. Journal of Applied Meteorology and Climatology, 52(9):2051-2064, May 2013. ISSN 1558-8424. doi: 10.1175/JAMC-D-13-02.1. URL http://journals.ametsoc.org/doi/abs/10.1175/ JAMC-D-13-02.1.

[13] Patricia Romero-Lankao, Hua Qin, and Katie Dickinson. Urban vulnerability to temperature-related hazards: A meta-analysis and meta-knowledge approach. Global Environmental Change, 22(3):670-683, August 2012. ISSN 0959-3780. doi: 10.1016/ j.gloenvcha.2012.04.002. URL http://www.sciencedirect.com/science/article/pii/ S0959378012000490.

[14] Howard Frumkin. Urban sprawl and public health. Public health reports, 2016. 
[15] Rupa Basu. High ambient temperature and mortality: a review of epidemiologic studies from 2001 to 2008. Environmental Health, 8(1):40, 2009. ISSN 1476-069X. doi: 10.1186/ 1476-069X-8-40. URL http://www.ehjournal.net/content/8/1/40.

[16] Daniel Oudin Åström, Forsberg Bertil, and Rocklöv Joacim. Heat wave impact on morbidity and mortality in the elderly population: A review of recent studies. Maturitas, 69(2): 99-105, June 2011. ISSN 0378-5122. doi: 10.1016/j.maturitas.2011.03.008. URL http: //www.sciencedirect.com/science/article/pii/S0378512211000806.

[17] Peter J Robinson. On the Definition of a Heat Wave. Journal of Applied Meteorology, 40 (4):762-775, 2001. URL http://journals.ametsoc.org/doi/abs/10.1175/1520-0450\% $282001 \% 29040 \% 3 \mathrm{C} 0762 \% 3$ AOTDOAH $\% 3 \mathrm{E} 2$. 0. CO $\% 3 \mathrm{~B} 2$.

[18] Tiffany T. Smith, Benjamin F. Zaitchik, and Julia M. Gohlke. Heat waves in the United States: definitions, patterns and trends. Climatic Change, 118(3-4):811-825, June 2013. ISSN 0165-0009, 1573-1480. doi: 10.1007/s10584-012-0659-2. URL http: //link.springer.com/article/10.1007/s10584-012-0659-2.

[19] Carina J. Gronlund. Racial and Socioeconomic Disparities in Heat-Related Health Effects and Their Mechanisms: a Review. Current Epidemiology Reports, pages 1-9, July 2014. ISSN 2196-2995. doi: 10.1007/s40471-014-0014-4. URL http://link.springer . com/article/10.1007/s40471-014-0014-4.

[20] Shakoor Hajat, Madeline O'Connor, and Tom Kosatsky. Health effects of hot weather: from awareness of risk factors to effective health protection. The Lancet, 375(9717):856863, March 2010. ISSN 0140-6736. doi: 10.1016/S0140-6736(09)61711-6. URL http: //www.sciencedirect.com/science/article/pii/S0140673609617116.

[21] R. Sari Kovats and Shakoor Hajat. Heat Stress and Public Health: A Critical Review. Annual Review of Public Health, 29(1):41-55, 2008. doi: 10.1146/annurev.publhealth. 29.020907.090843. URL http://dx.doi.org/10.1146/annurev.publhealth.29.020907. 090843.

[22] Evan R. Kuras, M. Bernhard, M. Calkins, K. Ebi, J. Hess, K. Kintziger, M. Jagger, Ariane Middel, Anna A. Scott, and J. Spector. Opportunities and challenges for personal heat exposure research. Environmental Health Perspectives, 85001:1, 2017.

[23] W. Neil Adger. Vulnerability. Global Environmental Change, 16(3):268-281, August 
2006. URL http://www.sciencedirect.com.ezaccess.libraries.psu.edu/science/ article/B6VFV-4KFMM81-2/2/22ffaffffa0ef5f8451decd3ed9240c3.

[24] Torsten Grothmann and Anthony Patt. Adaptive capacity and human cognition: the process of individual adaptation to climate change. Global Environmental Change Part A, 15(3): 199-213, October 2005.

[25] Robert W. Kates. Natural hazard in human ecological perspective: hypotheses and models. Economic Geography, 47(3):438-451, July 1971. ISSN 00130095. URL http://www.jstor. org.ezaccess.libraries.psu.edu/stable/142820. ArticleType: primary_article/Full publication date: Jul., 1971 / Copyright (C) 1971 Clark University.

[26] Paul Slovic. Perception of risk. Science, 236(4799):280-285, April 1987. doi: 10.1126/ science.3563507. URL http://www.sciencemag.org/cgi/content/abstract/236/4799/ 280.

[27] Gisela Wachinger, Ortwin Renn, Chloe Begg, and Christian Kuhlicke. The risk perception paradox - implications for governance and communication of natural hazards. Risk Analysis, 33(6):1049-1065, 2013. ISSN 1539-6924. doi: 10.1111/j.1539-6924.2012.01942.x. URL http: //onlinelibrary.wiley.com/doi/10.1111/j.1539-6924.2012.01942.x/abstract.

[28] Colleen E. Reid, Marie S. O’Neill, Carina J. Gronlund, Shannon J. Brines, Daniel G. Brown, Ana V. Diez-Roux, and Joel Schwartz. Mapping Community Determinants of Heat Vulnerability. Environmental Health Perspectives, 117(11):1730-1736, November 2009. ISSN 00916765. doi: 10.1289/ehp.0900683. URL http://www.ncbi.nlm.nih.gov/pmc/articles/ PMC2801183/.

[29] Vanessa Abrahamson, Johanna Wolf, Irene Lorenzoni, Bridget Fenn, Sari Kovats, Paul Wilkinson, W. Neil Adger, and Rosalind Raine. Perceptions of heatwave risks to health: interview-based study of older people in London and Norwich, UK. Journal of Public Health, 31(1):119-126, March 2009. ISSN 1741-3842, 1741-3850. doi: 10.1093/pubmed/fdn102. URL http://jpubhealth.oxfordjournals.org/content/31/1/119.

[30] Monika Nitschke, Alana Hansen, Peng Bi, Dino Pisaniello, Jonathan Newbury, Alison Kitson, Graeme Tucker, Jodie Avery, and Eleonora Dal Grande. Risk factors, health effects and behaviour in older people during extreme heat: a survey in South Australia. International Journal of Environmental Research and Public Health, 10(12):6721-6733, December 2013. ISSN 1660-4601. doi: 10.3390/ijerph10126721. 
[31] Natalie R. Sampson, Carina J. Gronlund, Miatta A. Buxton, Linda Catalano, Jalonne L. White-Newsome, Kathryn C. Conlon, Marie S. O’Neill, Sabrina McCormick, and Edith A. Parker. Staying cool in a changing climate: Reaching vulnerable populations during heat events. Global Environmental Change, 23(2):475-484, April 2013. ISSN 0959-3780. doi: 10. 1016/j.gloenvcha.2012.12.011. URL http://www.sciencedirect.com/science/article/ pii/S0959378013000022.

[32] Scott C. Sheridan. A survey of public perception and response to heat warnings across four North American cities: an evaluation of municipal effectiveness. International Journal of Biometeorology, 52(1):3-15, October 2007. ISSN 0020-7128, 1432-1254. doi: 10.1007/s00484-006-0052-9. URL http://link.springer.com/article/10.1007/ s00484-006-0052-9.

[33] Jan C. Semenza, Daniel J. Wilson, Jeremy Parra, Brian D. Bontempo, Melissa Hart, David J. Sailor, and Linda A. George. Public perception and behavior change in relationship to hot weather and air pollution. Environmental Research, 107(3):401-411, July 2008. ISSN 0013-9351. doi: doi:DOI:10.1016/j.envres.2008.03.005. URL http://www.sciencedirect. com/science/article/B6WDS-4SFR7TT-1/2/0bf1709a16b1d3c3bc4b8a45fa74c9a8.

[34] Johanna Wolf, W Neil Adger, and Irene Lorenzoni. Heat waves and cold spells: an analysis of policy response and perceptions of vulnerable populations in the UK. Environment and Planning A, 42(11):2721 - 2734, 2010. doi: 10.1068/a42503. URL http://www.envplan. com/abstract. cgi?id=a42503.

[35] WHO. Improving Public Health Responses to Extreme Weather/HeatWaves-EuroHEAT: Technical Summary. Technical report, World Health Organization Regional Office for Europe, Copenhagen, Denmark, 2009. URL ImprovingPublicHealthResponsestoExtremeWeather/Heat-WavesâĂŤEuroHEAT: TechnicalSummary.

[36] Olga V. Wilhelmi and Mary H. Hayden. Connecting people and place: a new framework for reducing urban vulnerability to extreme heat. Environmental Research Letters, 5(1): 014021, January 2010. ISSN 1748-9326. doi: 10.1088/1748-9326/5/1/014021. URL http: //iopscience.iop.org/1748-9326/5/1/014021.

[37] John P. Dunne, Ronald J. Stouffer, and Jasmin G. John. Reductions in labour capacity from heat stress under climate warming. Nature Climate Change, 2013. ISSN 1758-678X. doi: 10. 
1038/nclimate1827. URL http://www.nature.com/nclimate/journal/vaop/ncurrent/ full/nclimate1827.html.

[38] Michael E. Mann, Stefan Rahmstorf, Kai Kornhuber, Byron A. Steinman, Sonya K. Miller, and Dim Coumou. Influence of Anthropogenic Climate Change on Planetary Wave Resonance and Extreme Weather Events. Scientific Reports, 7:srep45242, March 2017. ISSN 2045-2322. doi: 10.1038/srep45242. URL https://www.nature.com/articles/srep45242.

[39] David K. Park, Andrew Gelman, and Joseph Bafumi. Bayesian Multilevel Estimation with Poststratification: State-Level Estimates from National Polls. Political Analysis, 12(4):375 -385, November 2004. doi: 10.1093/pan/mph024. URL http://pan.oxfordjournals. org/content/12/4/375. abstract.

[40] J. R Lax and J. H Phillips. How Should We Estimate Public Opinion in the States? American Journal of Political Science, 53(1):107-121, 2009.

[41] M. K. Buttice and B. Highton. How Does Multilevel Regression and Poststratification Perform with Conventional National Surveys? Political Analysis, 21(4):449-467, September 2013. ISSN 1047-1987, 1476-4989. doi: 10.1093/pan/mpt017. URL http: //pan.oxfordjournals.org/cgi/doi/10.1093/pan/mpt017.

[42] Peter D. Howe, Matto Mildenberger, Jennifer R. Marlon, and Anthony Leiserowitz. Geographic variation in opinions on climate change at state and local scales in the USA. $\mathrm{Na}$ ture Climate Change, 5:596-603, April 2015. ISSN 1758-678X. doi: 10.1038/nclimate2583. URL http://www.nature.com/nclimate/journal/vaop/ncurrent/full/nclimate2583. html.

[43] Matto Mildenberger, Jennifer R. Marlon, Peter D. Howe, and Anthony Leiserowitz. The spatial distribution of Republican and Democratic climate opinions at state and local scales. Climatic Change, 145(3-4):539-548, December 2017. ISSN 0165-0009, 1573-1480. doi: 10.1007/s10584-017-2103-0. URL https://link.springer.com/article/10.1007/ s10584-017-2103-0.

[44] Paul Knox and Steven Pinch. Urban social geography: an introduction. Routledge, 2014.

[45] Sharon L. Harlan, Anthony J. Brazel, Lela Prashad, William L. Stefanov, and Larissa Larsen. Neighborhood microclimates and vulnerability to heat stress. Social Science \&3 Medicine, 63(11):2847-2863, December 2006. ISSN 0277-9536. doi: 10.1016/ 
j.socscimed.2006.07.030. URL http://www.sciencedirect.com/science/article/pii/ S027795360600373X.

[46] Centers for Disease Control and Prevention, National Center for Health Statistics. Multiple Cause of Death 1999-2015 on CDC WONDER Online Database, December 2016. URL http://wonder.cdc.gov/mcd-icd10.html.

[47] Jerry M Melillo. Climate change impacts in the United States: the third national climate assessment. Government Printing Office, 2014.

[48] Friederike EL Otto, N Massey, GJ Oldenborgh, RG Jones, and MR Allen. Reconciling two approaches to attribution of the 2010 russian heat wave. Geophysical Research Letters, 39 (4), 2012.

[49] Noah S Diffenbaugh and Martin Scherer. Observational and model evidence of global emergence of permanent, unprecedented heat in the 20th and 21st centuries. Climatic Change, 107(3-4):615-624, 2011.

[50] Jennifer F. Bobb, Roger D. Peng, Michelle L. Bell, and Francesca Dominici. Heat-Related Mortality and Adaptation to Heat in the United States. Environmental Health Perspectives, April 2014. ISSN 0091-6765. doi: 10.1289/ehp.1307392. URL http://ehp.niehs.nih.gov/ $1307392 /$.

[51] Andy Liaw and Matthew Wiener. Classification and regression by randomforest. $R$ News, 2(3):18-22, 2002. URL http://CRAN.R-project.org/doc/Rnews/.

[52] P.E. Thornton, M.M. Thornton, B.W. Mayer, Y. Wei, R. Devarakonda, R. S Vose, and R.B. Cook. Daymet: Daily Surface Weather Data on a 1-km Grid for North America; Version 3, 2017. URL https://doi.org/10.3334/ORNLDAAC/1328.

[53] George Xian, Collin Homer, Jon Dewitz, Joyce Fry, Nazmul Hossain, and James Wickham. Change of impervious surface area between 2001 and 2006 in the conterminous United States. Photogrammetric Engineering and Remote Sensing, 77(8):758-762, 2011. URL https://pubs.er.usgs.gov/publication/70036044.

[54] U. S. Census Bureau. 2010-2014 American Community Survey 5-Year Estimates, 2015. URL http://www.census.gov/programs-surveys/acs/about.html. 